${ }^{1}$ Departamento de Medicina Interna.

2Sección de Nefrología, Departamento de Medicina Interna. Hospital Clínico de la Universidad de Chile. Santiago de Chile.

Declaración de conflictos de intereses: Los autores declararon no tenerlos.

Recibido el 11 de julio de 2013, aceptado el 6 de noviembre de 2013.

Correspondencia a: Dra. María Eugenia Sanhueza. Departamento de Nefrología, Hospital Clínico Universidad de Chile.

Santos Dumont 999 Independencia, Santiago, Chile. Teléfono: 29788423 - Fax: 27352964 hemofiltración@gmail.com

\section{Caso clínico: cistitis enfisematosa asociada a hidronefrosis secundaria}

\author{
EDITH PÉREZ DE ARCE OÑATE ${ }^{1}$, MARÍA EUGENIA SANHUEZA², \\ RUBÉN TORRES ${ }^{2}$, ERICO SEGOVIA ${ }^{2}$
}

\section{Emphysematous cystitis. Report of one case}

We report a 53 year-old woman with type 2 diabetes mellitus and hypertension, presenting with progressive abdominal pain lasting three weeks, associated with lower abdominal swelling and fever. Clinical examination showed a large increase in abdominal volume, contraction of extracellular compartment, and signs of severe sepsis. Computed tomography showed an over-distended bladder with severe wall and luminal pneumatosis and bilateral hydronephrosis. The diagnosis was of emphysematous cystitis associated to hydronephrosis. Urine and blood cultures were positive for multi-susceptible Escherichia coli. Clinical evolution was favorable after 6 weeks of ceftriaxone and urinary catheter use. Emphysematous cystitis is a rare clinical entity, with an associated mortality of 7\%. Known predisposing factors are older age, female gender and presence of diabetes. Microbiological agents most frequently involved are Escherichia coli and Klebsiella pneumoniae (80\% of cases). Medical treatment is preferred and is based on urinary tract decompression with a bladder catheter, and prolonged broad spectrum antimicrobial therapy.

(Rev Med Chile 2014; 142: 114-117)

Key words: Cystitis, emphysematous; Escherichia coli; Hydronephrosis.
$\mathrm{L}$ a cistitis enfisematosa es una enfermedad poco frecuente que se caracteriza por la presencia de gas en el interior de la vejiga, en la pared vesical o en ambas, producida habitualmente por bacilos aerobios Gram negativos, capaces de formar gas. Los factores de riesgo que predisponen a esta patología son la diabetes mellitus, el sexo femenino, infección urinaria a repetición, obstrucciones del tracto urinario, vejiga neurogénica y estados de inmunosupresión. Su diagnóstico se basa en un alto índice de sospecha en pacientes con factores de riesgo y los hallazgos característicos en las imágenes (radiología simple y tomografía computarizada).

Comunicamos un caso clínico con una forma atípica de presentación.

\section{Caso clínico}

Mujer de 53 años, con antecedentes de diabetes mellitus tipo 2, hipertensión arterial crónica y vejiga neurogénica. Consultó por tres semanas de compromiso del estado general, calofríos, sensación febril no cuantificada, incontinencia urinaria, dolor hipogástrico y aumento de volumen abdominal progresivo.

Ingresó a nuestro servicio obnubilada, deshidratada, mal perfundida, yugulares planas, temperatura $37,8^{\circ} \mathrm{C}$, PA de $100 / 60 \mathrm{mmHg}$, frecuencia cardiaca de 114 latidos por min. En el examen se palpó una masa sensible, desde el epigastrio hasta la sínfisis pubiana. Al ingreso destacaron en los exámenes: glicemia de $641 \mathrm{mg} / \mathrm{dl}, \mathrm{Hb}$ glicosilada $9,5 \%$, hematocrito $35,9 \%$, leucocitosis $20.000 \mathrm{x}$ $\mu \mathrm{L}, \mathrm{PCR} 130$, sodio plasmático $117 \mathrm{mEq} / \mathrm{L}$, potasio plasmático $5,3 \mathrm{mEq} / \mathrm{L}$, creatininemia $0,9 \mathrm{mg} / \mathrm{dL}$, nitrógeno ureico de $35 \mathrm{mg} / \mathrm{dl}$ y examen de orina con glucosuria $500 \mathrm{mg} / \mathrm{dL}$, leucocituria $40-50$ por campo, eritrocitos $80-90$ por campo, bacterias abundantes.

Se realizó una pielo TAC al ingreso, que mostró una vejiga muy distendida, con un volumen 

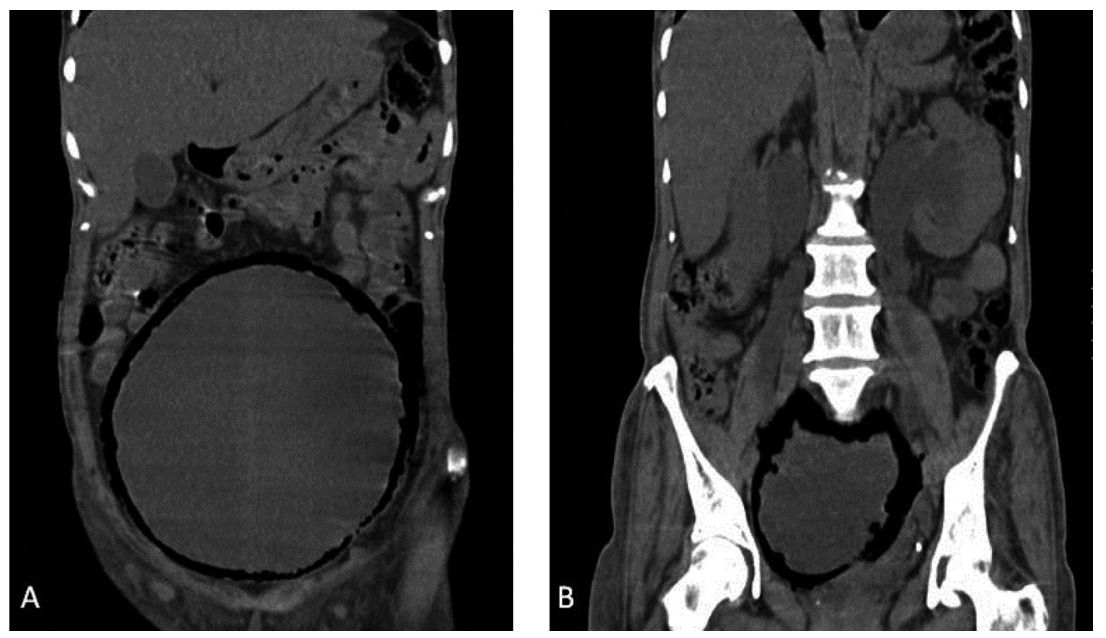

Figura 1. Pielo TAC al ingreso. (A) Gran distensión vesical y pneumatosis en la pared vesical asociado a gas intraluminal. (B) Hidroureteronefrosis bilateral asociada a cistitis enfisematosa.
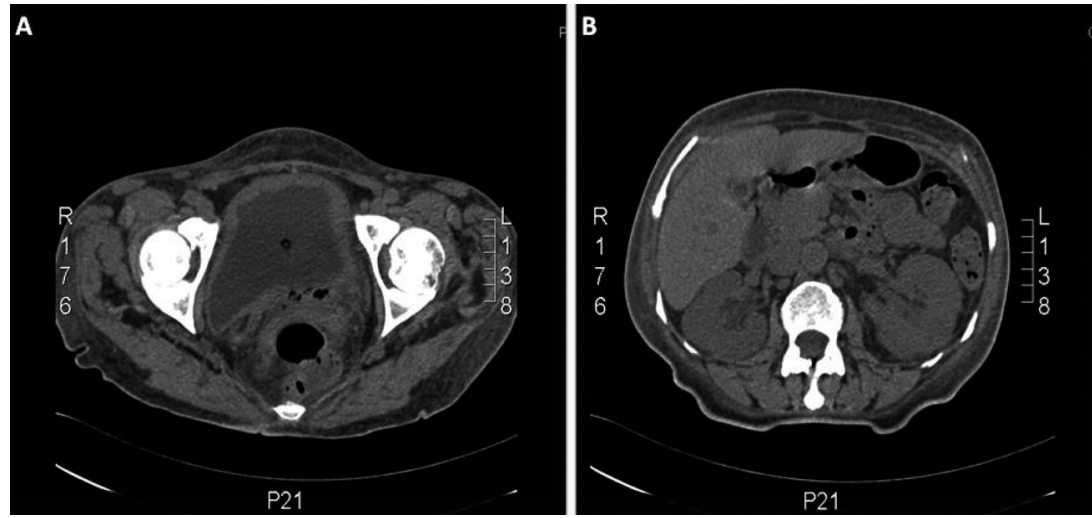

Figura 2. Pielo TAC a los 15 días de terapia. (A) regresión de la cistitis enfisematosa. (B) regresión de la hidroureteronefrosis.

estimado de $2.340 \mathrm{ml}$, con pneumatosis severa en la pared vesical y gas intraluminal. Los riñones se observaron con aumento tenue del tejido adiposo circundante, ambos con moderada hidroureteronefrosis (Figura 1).

Se diagnosticó una cistitis enfisematosa asociada a hidroureteronefrosis bilateral.

La paciente se trató inicialmente descomprimiendo la vía urinaria con sonda Foley, que dio salida a orina de aspecto turbio y abundante gas. Se hidrató hasta corregir el déficit de VEC y los trastornos hidroelectrolíticos. La hiperglicemia se corrigió con insulina. Previa toma de cultivos, se inició tratamiento antibiótico empírico con ceftriaxona y amikacina endovenosa. Urocultivo y hemocultivos fueron positivos para Escherichia coli multisensible. Su evolución clínica fue favorable, completando 6 semanas de tratamiento antibiótico con ceftriaxona. En las imágenes de control previas al alta se comprobó una regresión de la neumatosis de la pared vesical y de la hidroureteronefrosis inicial (Figura 2).

\section{Discusión}

La cistitis enfisematosa es una enfermedad muy infrecuente, descrita en el año 1671 en un hombre con pneumaturia. Posteriormente, esta condición fue descrita en varias series de autopsias, hasta que en 1961 Bailey acuñó el término de "cistitis enfisematosa" recolectando una serie de 19 casos $^{1}$. En una revisión de Thomas de 135 casos de cistitis enfisematosa, se reportó una media de edad de 66 años, la mayoría de sexo femenino (64\%) y con antecedente de diabetes mellitus (67\%), siendo 
esta la comorbilidad más frecuente ${ }^{2}$. Factores de riesgo de la enfermedad incluyen edad avanzada, sexo femenino, diabetes mellitus, vejiga neurogénica, uso de catéter vesical, fístula vesico-rectal, enfermedad renal en etapa avanzada y uropatía obstructiva $^{3-4}$.

Su patogenia es aún poco clara. Al contrario de lo que se cree, sólo en un bajo porcentaje de los casos se ha comprobado una infección por anaerobios. La mayoría de los microorganismos aislados corresponden a bacilos Gram negativos anaerobios facultativos, que en un ambiente favorable rico en glucosa son capaces de producir gas a través del proceso de fermentación, acumulándose gas en las paredes y el lumen vesical ${ }^{10}$. En pacientes no diabéticos influirían otros factores como la albuminuria y el compromiso vascular local, que puede resultar en malabsorción de gas debido al incremento de la presión intravesical ${ }^{4}$. El agente más frecuentemente aislado en diferentes reportes corresponde a Escherichia coli (58\%), seguido de Klebsiella pneumoniae (21\%) $)^{3-4}$. Otros agentes identificados incluyen Enterococcus y Candida albicans, siendo algunas infecciones polimicrobianas. Menos del 10\% de los casos corresponden a bacterias anaerobias.

Como síntomas de presentación los casos publicados incluyen dolor abdominal severo $(80 \%)$, retención urinaria $(60 \%)$, fiebre $(52 \%)$, hematuria $(47 \%)$, disuria $(45 \%)$, polaquiuria (44\%). En los pacientes diabéticos con vejiga neurogénica, los síntomas pueden ser inespecífi$\cos ^{4,5}$. Más específico pero menos frecuente es la presencia de pneumaturia en la historia clínica (26\%). Puede asociarse a pielonefritis enfisematosa aumentando la mortalidad desde $7 \%$ a $14 \%$. El examen de orina revela piuria y hematuria, con urocultivo positivo en más de $90 \%$ de los casos y hemocultivos positivos en la mitad de ellos ${ }^{5}$. Los parámetros inflamatorios se encuentran alterados en $80 \%$ de los casos (PCR elevada, leucocitosis con desviación izquierda, VHS elevada), asociándose con aparición de insuficiencia renal aguda en la mitad de ellos ${ }^{5}$. La cistitis enfisematosa puede ser diagnosticada por imágenes, por visualización directa con cistoscopía, durante una laparotomía, o por biopsia de vejiga ${ }^{2}$. Los hallazgos de imágenes pueden proporcionar la primera clave diagnóstica ${ }^{6,9}$. La radiografía de abdomen simple puede mostrar una línea radiolúcida circundando la pared vesical, nivel hidroaéreo intravesical, o burbujas adyacentes a la mucosa que simulan un "collar de cuentas". La ecografía puede mostrar engrosamiento de la pared vesical, pero su sensibilidad es baja. La tomografía axial computada es el examen de elección, con una alta sensibilidad y especificidad, que permite identificar gas en la pared vesical y/o en el lumen de la vía urinaria, además de objetivar la presencia de gas en el parénquima renal, lo que constituye el diagnóstico de pielonefritis enfisematosa.

El tratamiento médico es de elección, corresponde a reposición de volumen y manejo del shock, control metabólico, descompresión vesical, y uso de antibióticos por vía parenteral. Los antibióticos de amplio espectro son de elección (fluorquinolonas, beta lactámicos asociados a inhibidores de beta lactamasas, cefalosporinas de $3^{a}$ generación, carbapenémicos) de acuerdo a la etiología microbiana, realizando ajuste de terapia según los cultivos. El tratamiento con antibióticos debe prolongarse por un mínimo de 3 a 6 semanas. A diferencia de la pielonefritis enfisematosa que frecuentemente termina en nefrectomía, la cistitis enfisematosa rara vez requiere tratamiento quirúrgico, siendo este necesario a veces frente a malformaciones de la vía urinaria o complicaciones tales como una progresión a cistitis necrotizante grave o la formación de abscesos, rotura vesical, requiriendo desde debridamiento quirúrgico hasta cistectomía.

Como observamos en este caso clínico, la cistitis enfisematosa puede ocasionalmente asociarse a hidroureteronefrosis bilateral, en el contexto de una inflamación vesical severa asociada a vejiga neurogénica, la que experimenta una resolución completa al término del tratamiento.

La cistitis enfisematosa es una patología infrecuente, pero potencialmente letal, en que se debe tener un alto índice de sospecha, sobretodo en pacientes diabéticos descompensados, con infección urinaria.

\section{Referencias}

1. Bailey H. Cystitis emphysematosa; 19 cases with intraluminal and intersticial collections of gas. Am J Roentgenol Rodium Ther Nucl Med 1961; 86: 850-62.

2. Thomas AA, Lane BR, Thomas AZ, Remer EM, Campbell SC, Schoskes DA. Emphysematous cystitis: a review of 135 cases. BJU Int 2007; 100 (1): 17-20. 
3. Karashima E, Ejima J, Nakamura H, Koike A, Kaneko T, Ohmura I. Emphysematous cistitis with venous bubbles. Internal Medicine 2005; 44 (6): 590-2.

4. Yoshida K, Murao K, Fukuda N, Tamuran Y, Ishida T. Emphysematous Cystitis with Diabetic Neurogenic Bladder. Internal Medicine 2010; 49: 1879-83.

5. Grupper M, Kravtsov A, Potasman I. Emphysematous Cystitis. Illustrative Case Report and Review of the Literature. Medicine 2007; 86 (1): 47-53.

6. Santos-Sánchez JA, Martín-Sánchez MJ, Díez-Hernández JC, Asensio-Calleb JF, Sánchez-Martínc L. Cistitis enfisematosa. Valor de las pruebas de imagen. Rev Esp Geriatr Gerontol 2005; 40 (2): 126-8.

7. Pérez Fentes D, Blanco Parra M, Lema Grille J, Toucedo
Caamaño V, Novas Castro S, Lamas Cedron P, Villar Núñez M. Emphysematous cystitis: case report. Arch. Esp Urol 2009; 62 (5): 392-5.

8. Galiano Baena JF, Caballero Romeu JP, Galán Llopis JA, Leivar Tamayo A, Lobato Encinas JJ. Ncjued. Cistitis enfisematosa. Caso clínico y revisión de literatura. Actas Urol Esp 2008; 32 (9): 948-50.

9. Bobba R, Arsura E, Sarna P, Sawh A. Case report. Emphysematous cystitis: An unusual disease of the Genito-Urinary system suspected on imaging. Ann Clin Microbiol Antimicrob 2004; 3: 20-3.

10. Huang JJ, Chen KW, Ruaan MK. Mixed acid fermentation of glucose as a mechanism of emphysematous urinary tract infection. J Urol 1991; 146: 148-51. 